\title{
ABBREVIATIONS
}

$\begin{array}{ll}\text { ASU } & \text { Anti-Socialist Union } \\ \text { BBL } & \text { British Brothers' League } \\ \text { BCCSE } & \text { British Council for Christian Settlement in Europe } \\ \text { BCU } & \text { British Commonwealth Union } \\ \text { BEFP } & \text { British Empire Fascist Party } \\ \text { BEU } & \text { British Empire Union } \\ \text { BF } & \text { British Fascisti, British Fascists Ltd } \\ \text { BPP } & \text { British People's Party } \\ \text { BUF } & \text { British Union of Fascists } \\ \text { BWL } & \text { British Workers' League } \\ \text { CINEF } & \text { Centre International d'Etudes sur la Fascisme (Inter- } \\ & \text { national Centre of Fascist Studies) } \\ \text { CPGB } & \text { Communist Party of Great Britain } \\ \text { EL } & \text { Economic League } \\ \text { IFL } & \text { Imperial Fascist League } \\ \text { ILP } & \text { Independent Labour Party } \\ \text { LCC } & \text { London County Council } \\ \text { MCP } & \text { Militant Christian Patriots } \\ \text { NCCL } & \text { National Council for Civil Liberties } \\ \text { NCU } & \text { National Citizens' Union } \\ \text { NF } & \text { National Fascisti } \\ \text { NL } & \text { Nordic League } \\ \text { NP } & \text { National Party } \\ \text { NPL } & \text { National Political League } \\ \text { NSDAP } & \text { Nationalsocialistische Deutsche Arbeiterpartei (Na- } \\ & \text { tional Socialist German Workers' Party) } \\ \text { NSL } & \text { National Service League } \\ \text { NSL } & \text { National Socialist League } \\ \text { NWP } & \text { National Workers' Party } \\ & \end{array}$

xii 
PEP Political and Economic Planning

PNF Partito Nazionale Fascista (Italian Fascist Party)

UBP United British Party

\section{Abbreviations used in the notes}

BD Board of Deputies of British Jews, Woburn House, London

BUQ British Union Quarterly

FQ Fascist Quarterly

HO Home Office

JPC Jewish People's Council Against Fascism and AntiSemitism

MEPOL Metropolitan Police

NCCL National Council for Civil Liberties Archive, Brynmor Jones Library, University of Hull

PRO Public Record Office 
Thomas Linehan - 9781526162205 Downloaded from manchesterhive.com at 04/26/2023 02:52: 03PM 